\section{Optimal stimulating current for train-of-four stimulation in conscious subjects}

Yuhji Saitoh MD, Kohichi Nakazawa MD, Hidenori Toyooka MD, Keisuke Amaha MD
The purpose of this study was to determine the optimal stimulating current for train-of-four (TOF) monitoring with regard to the return of TOF response and the discomfort associated with TOF. Two variables were examined at 60, 50, 40,30, and $20 \mathrm{~mA}$ : (1) times from administration of vecuronium 80 $\mu \mathrm{g} \cdot \mathrm{kg}^{-1}$ to returns of responses to TOF determined accelographically in 75 anaesthetised patients and (2) discomfort associated with TOF in 15 awake volunteers using visual analogue scale (VAS). Times to return of the first response to stimulation at 60, 50, 40, and $30 \mathrm{~mA}$ were not different $(29.1 \pm 11.2,30.1$ $\pm 12.0,31.9 \pm 12.6$, and $35.4 \pm 14.2 \mathrm{~min}$, respectively, mean $\pm S D$ ). However, time to the return of the first response elicited at $20 \mathrm{~mA}(53.7 \pm 21.6)$ was longer than at higher currents $(P<0.05)$. Similarly, with regard to the second, third, and fourth responses, the time to the return at $20 \mathrm{~mA}$ was longer than at the other currents $(P<0.05)$. The VAS associated with TOF at 60, 50, 40,30, and $20 \mathrm{~mA}$ were $7.3 \pm 1.9,6.7$ $\pm 1.8,6.0 \pm 2.0,4.1 \pm 2.1$, and $2.7 \pm 2.3$, respectively. The $V A S$ at $30 \mathrm{~mA}$ was less than at 60 and $50 \mathrm{~mA}(P<0.05)$, and at $20 \mathrm{~mA}$ was less than at 60,50 , and $40 \mathrm{~mA}(P<$ 0.05). In conclusion it is suggested that, when testing conscious patients, $30 \mathrm{~mA}$ is the optimal stimulating current for TOF monitoring because it represents the best compromise of neuromuscular monitoring and patient discomfort.

Cette étude vise à déterminer le stimulus nécessaire au monitorage du train-de-quatre (TOF) relativement au retour de la réponse au TOF et à línconfort qui y est associé. Deux

Key words

MEASUREMENT TECHNIQUES: neuromuscular blockade, train-of-four;

NEUROMUSCULAR RELAXANTS: vecuronium

From the Department of Anesthesiology and Critical Care Medicine, Faculty of Medicine, Tokyo Medical and Dental University, Tokyo, Japan.

Address correspondence to: Dr. Y. Saitoh, Department of Anesthesiology and Critical Care Medicine, Faculty of Medicine, Tokyo Medical and Dental University, 5-45, Yushima, 1-Chome, Bunkyo-ku, Tokyo 113, Japan.

Accepted for publication 8th July, 1995. paramètres sont évalués à $60,50,40,30$, et $20 \mathrm{~mA}$ : I) lintervalle entre l'administration du vécuronium $80 \mu \mathrm{g} \cdot \mathrm{kg}^{-1}$ et le retour de la réponse au TOF évalué par accélérographie chez 75 patients anesthésiés et 2) linconfort associé au TOF évalué sur une échelle visuelle analogique (EVA) chez 15 volontaire éveillés. Les intervalles précédant le retour de la première réponse à 60, 50, 40 et $30 \mathrm{~mA}$ ne sont pas différents (respectivement 29,1 $\pm 11,2,30,1 \pm 12,0,31,9 \pm 12,6$ et $35,4 \pm 14,2$, moyenne $\pm E T$. Cependant, lintervalle précédant le retour de la première réponse élicitée à $20 \mathrm{~mA}(53,7 \pm 21,6)$ est plus long qu'à des ampérages plus élevés $(P<0,05)$. Les EVA associées au TOF à $60,50,40,30$ et $20 \mathrm{~mA}$ sont respectivement de $7,3 \pm 1,9,6,7 \pm 1,8,6,0 \pm 2,0,4,1 \pm 2,1$ et $2,7 \pm 2,3$. L'EVA à $30 \mathrm{~mA}$ est moindre quà 60 et $50 \mathrm{~mA}(P<0,05)$ et à 20 $m A$, moindre qu'à 60, 50 et $40 \mathrm{~mA}(P<0,05)$. En conclusion, les auteurs suggèrent que lorsquil faut évaluer des patients conscients, $30 \mathrm{~mA}$ représente le courant optimal pour le monitorage du TOF parce quill siagit là du meilleur compromis utilisable pour le monitorage neuromusculaine et le confor du patient.

Recently, the usefulness of submaximal stimulation to evaluate the degree of neuromuscular blockade has been reported. ${ }^{1-4}$ Ulnar nerve stimulation at submaximal current can be performed, even in awake patients, because it is less uncomfortable than that at supramaximal stimulation. ' Furthermore, the train-of-four ratio (TOFR, $T_{4} / T_{1}$ ) remained consistent over a wide range of stimulating currents. ${ }^{2-4}$ To determine recovery from neuromuscular blockade, not only the TOFR but also the times to return of the first, second, third, and fourth responses to TOF stimulation are important. However, the times to return of TOF responses at varying currents during recovery from non-depolarising neuromuscular blockade have not been reported. In this study, both the times to return of TOF responses after administration of vecuronium and the discomfort resulting from TOF stimulation at varying currents were examined.

Methods

Seventy-five adult patients (40 male and 35 female) with 
ASA physical status 1 or 2 scheduled for elective surgical procedures and 15 healthy volunteers (eight male and seven female) who were not medicated were studied. The protocol was approved by the institutional human investigation committee. Written informed consent was obtained from each subject, and verbal informed consent was acquired from each volunteer. Patients and volunteers who had neuromuscular, renal or hepatic disorders or who were taking any drug known to affect neuromuscular transmission were excluded. The patients were allocated randomly to five groups of 15 patients. When the wrist circumference was $>16 \mathrm{~cm}$, they were excluded from the study because wrists of this size require currents $>40$ $\mathrm{mA}$ to achieve supramaximal muscular responses. ${ }^{5}$

Premedication, atropine $0.01 \mathrm{mg} \cdot \mathrm{kg}^{-1}$ and hydroxyzine $1 \mathrm{mg} \cdot \mathrm{kg}^{-1}$ was given $30 \mathrm{~min}$ preoperatively. Two stimulating surface electrodes (Vitrode, M-150, NihonKohden, Tokyo, Japan) were positioned over the ulnar nerve of the forearm contralateral to the blood pressure cuff. The distal electrode (negative) was placed about 1 $\mathrm{cm}$ proximal to the point where the proximal flexion crease of the wrist crossed the radial side of the tendon to the ulnar flexor carpi muscle, and the proximal electrode (positive) was placed $2-3 \mathrm{~cm}$ proximal to the distal electrode according to previous reports. ${ }^{6,7}$ An accelographic transducer (Accelographic transducer, ACC-007, Biometer International, Odense, Denmark) was placed on the volar aspect of the thumb. Anaesthesia was induced with thiopentone $5.0 \mathrm{mg} \cdot \mathrm{kg}^{-1} i v$, and was maintained with nitrous oxide $66 \%$ in oxygen and $1.0 \%$ end-tidal isoflurane. Tracheal intubation was facilitated with succinylcholine $1.0 \mathrm{mg} \cdot \mathrm{kg}^{-1} \dot{\boldsymbol{v}}$ and ventilation was controlled to maintain normocapnia (PETCO $30-35 \mathrm{mmHg}$ ). Concentrations of carbon dioxide, nitrous oxide, oxygen, and isoflurane were measured using a multiple gas analyser (Capnomac-Ultima, S-31-03, Datex, Inc., Helsinki, Finland). These anaesthetic concentrations were maintained until $T_{4}$ (the fourth response to train-of-four (TOF) stimulation) appeared. Peripheral skin temperature over the adductor pollicis muscle of the investigated arm was measured using a thermometer (Terumo-Finer, CTM303, Terumo, Tokyo, Japan) throughout anaesthesia.

Train-of-four square-wave impulses at $2 \mathrm{~Hz}$ frequency and $0.2 \mathrm{msec}$ duration were delivered at $60 \mathrm{~mA}$ every $12 \mathrm{sec}$ using an electrical stimulator (Myotest DBS, DBS$000 \mathrm{E}$, Biometer International, Odense, Denmark). The accelographic responses to TOF stimuli were demonstrated in a bed-side monitor (Life Scope 14, BSM-8800, Nihon-Kohden, Tokyo, Japan), and were recorded on a strip chart-recorder (Thermal Array Reconder, WS-841$R$, Nihon-Kohden, Tokyo, Japan) at a chart-speed of 1 $\mathrm{mm} \cdot \mathrm{sec}^{-1}$. When the accelographic values of $T_{1}$ (the first response to TOF stimulation) became stable, approxi- mately $20 \mathrm{~min}$ from the administration of succinylcholine, the accelographic value in response to $T_{1}$ was recorded as the control value and vecuronium $80 \mu \mathrm{g} \cdot \mathrm{kg}^{-1} i \nu$ was administered. Thereafter, the stimulating currents for TOF monitoring were adjusted to $60,50,40,30$, and $20 \mathrm{~mA}$ in group $60,50,50,40,30$, and 20 , respectively and the times from administration of vecuronium 80 $\mu \mathrm{g} \cdot \mathrm{kg}^{-1}$ to initial return of $T_{1}, T_{2}, T_{3}$, and $T_{4}$ responses were measured in the five groups. The first appearance of neuromuscular response to TOF stimulation which could be observed on the strip chart-recorder during recovery from neuromuscular blockade was regarded as the return of the response. At the end of surgery atropine $0.02 \mathrm{mg} \cdot \mathrm{kg}^{-1}$ and neostigmine $0.04 \mathrm{mg} \cdot \mathrm{kg}^{-1} \dot{\mathrm{v}}$ were administered to antagonise residual neuromuscular blockade.

To assess discomfort the 15 volunteers received TOF stimulation at $60,50,40,30$, and $20 \mathrm{~mA}$ in a blinded, randomised order. Prior to the assessment of the discomfort each volunteer received one of the five stimuli in order to minimise the element of surprise on subsequent testing. Discomfort associated with TOF stimulation was estimated using a visual analogue scale (VAS) after each volunteer had been instructed on its use. No discomfort was regarded as zero and the worst discomfort imaginable as ten.

All results are expressed as number of mean \pm SD. The patient data and the times to return of TOF responses were compared using Scheffe's test after analyses of variance (ANOVA). The VAS scores were compared using Mann-Whitney U test with Bonferroni's adjustment after Friedman's test. In all cases, $P<0.05$ was considered to be statistically significant. Statistical comparisons were performed using a statistical package. STAT FLEX: version 2 (Statview Inc., Tokyo, Japan) running on a personal computer (PC-9801 Ne, NEC Inc., Tokyo, Japan).

\section{Results}

There were no significant differences among groups regarding age, sex, height, or weight (Table). In no patient or volunteer was the circumference of the wrist above $16 \mathrm{~cm}$, and in no patient did the peripheral skin temperature decrease below $33^{\circ} \mathrm{C}$ throughout anaesthesia.

Times to the returns of TOF responses $\left(T_{1}, T_{2}, T_{3}\right.$, and $\left.T_{4}\right)$ in group $60,50,40$, and 30 were not different, but were delayed in group $20(P<0.05)$ (Figure 1). In each subject all TOF responses $\left(T_{1}, T_{2}, T_{3}\right.$, and $\left.T_{4}\right)$ were observed at the end of surgery, and after administration of atropine $0.02 \mathrm{mg} \cdot \mathrm{kg}^{-1}$ and neostigmine 0.04 $\mathrm{mg} \cdot \mathrm{kg}^{-1}$ TOF ratio $\left(\mathrm{T}_{4} / \mathrm{T}_{1}\right)$ became $>0.8$.

The VAS associated with TOF stimulation at $20 \mathrm{~mA}$ was less than those at 60,50 and $40 \mathrm{~mA}(P<0.05)$ and the VAS at $30 \mathrm{~mA}$ was smaller than those at 60 
TABLE Demographic data of the five groups of anaesthetized patients and the awake volunteers. Values are number or mean $\pm S D$

\begin{tabular}{lllllll}
\hline Group & 60 & 50 & 40 & 30 & 20 & Volunteers \\
\hline$n$ & 15 & 15 & 15 & 15 & 15 & 15 \\
Age (yr) & $47.2 \pm 6.1$ & $48.9 \pm 5.3$ & $49.0 \pm 5.0$ & $46.4 \pm 5.1$ & $49.4 \pm 5.9$ & $46.8 \pm 4.4$ \\
Sex (M/F) & $8 / 7$ & $8 / 7$ & $8 / 7$ & $8 / 7$ & $8 / 7$ & $8 / 7$ \\
Height $(\mathrm{cm})$ & $164.2 \pm 10.0$ & $166.0 \pm 9.8$ & $164.6 \pm 8.8$ & $160.8 \pm 8.6$ & $162.5 \pm 12.2$ & $163.3 \pm 7.8$ \\
Weight $(\mathrm{kg})$ & $56.0 \pm 8.4$ & $55.8 \pm 7.1$ & $56.4 \pm 7.4$ & $59.7 \pm 6.9$ & $58.3 \pm 6.2$ & $55.5 \pm 5.4$ \\
\hline
\end{tabular}

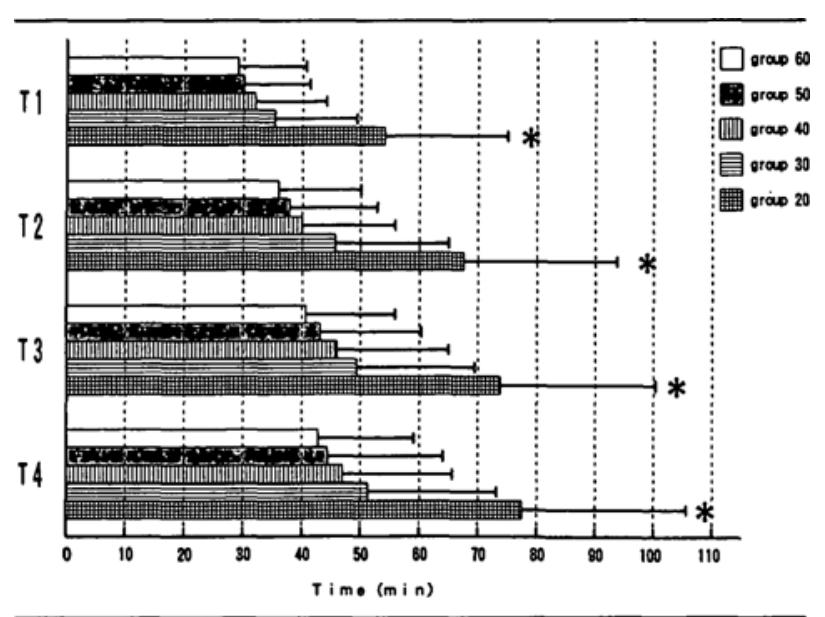

FIGURE 1 Times from administration of vecuronium $80 \mu \mathrm{g} \cdot \mathrm{kg}^{-1}$ to the return of TOF responses $\left(T_{1}, T_{2}, T_{3}\right.$, and $\left.T_{4}\right)$ in group 60,50, 40,30 , and $20 . * P<0.05$ group $60,50,40$, and 30 vs group 20 .

and $50 \mathrm{~mA}(P<0.05)$. No differences were observed between VAS at $30 \mathrm{~mA}$ and that at $20 \mathrm{~mA}$, nor among those at 60, 50, and $40 \mathrm{~mA}$ (Figure 2).

\section{Discussion}

To determine recovery from neuromuscular blockade not only TOFR but also the times to return of the first, second, third, and fourth responses to TOF stimulation are important. This study indicates that if the ulnar nerve is stimulated over a wide range of $30-60 \mathrm{~mA}$ the times from administration of vecuronium $80 \mu \mathrm{g} \cdot \mathrm{kg}^{-1}$ to return of TOF responses are similar. Only when the ulnar nerve is stimulated at $20 \mathrm{~mA}$ is the time to the return of TOF responses delayed. Kopman et al. ${ }^{5}$ reported that in the majority of anaesthetised patients ulnar nerve stimulation at $30 \mathrm{~mA}$ was capable of producing a supramaximal muscular contraction. Although in their study the current needed to produce a supramaximal muscular contraction was determined in the absence of nondepolarising neuromuscular relaxant, the present study showed that their findings also hold true after administration of vecuronium.

Brull $e$ t al. ${ }^{2,3}$ demonstrated that TOFR remained consistent over a wide range of stimulation currents and over

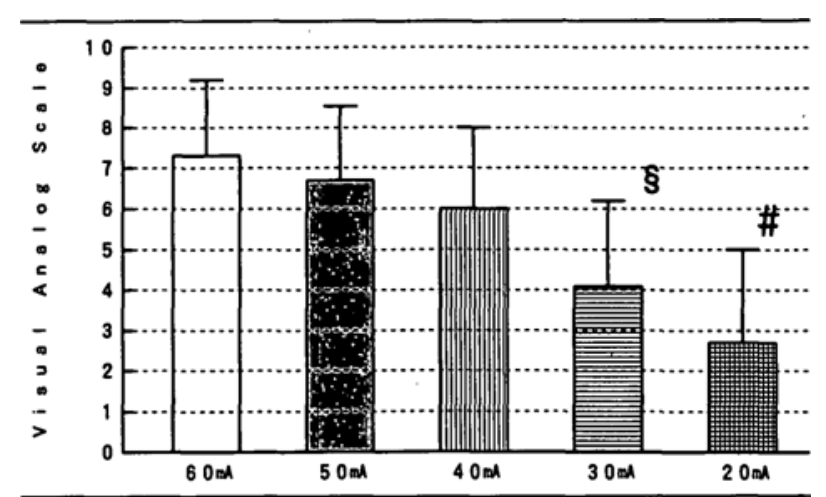

FIGURE 2 Visual Analogue Scales (VAS) associated with TOF stimuli over the ulnar nerve at $60,50,40,30$, and $20 \mathrm{~mA}$ in awake volunteers. $\S P<0.05$ VAS at $30 \mathrm{~mA}$ vs at 60 and $50 \mathrm{~mA}$. $\# P<0.05$ VAS at $20 \mathrm{~mA}$ vs at 60,50 , and $40 \mathrm{~mA}$.

a wide spectrum of depth of clinical neuromuscular blockade. They also noted that lower currents might be more practical in awake patients, because recordings of TOF responses at submaximal currents were as reliable as, and more comfortable than, monitoring at supramaximal current. However, no previous studies have determined the best stimulating current for TOF monitoring in awake subjects in view of the times to return of the individual responses to TOF stimulation. This study has suggested that in order to detect the presence or absence of twitches in TOF, not TOFR, the best stimulating current for TOF monitoring used in conscious patients as seen in the Post Anaesthetic Care Unit (PACU) and Intensive Care Unit (ICU) is $30 \mathrm{~mA}$.

It has been reported that nerve stimulation using sphericalended metal probes causes burn of the skin in anaesthetised patients. ${ }^{8,9} \mathrm{Kopman}$ et al. ${ }^{10}$ noted that ulnar nerve stimulation at supramaximal current using surface electrodes yielded no burns and was found to be safe compared with nerve stimulation using the sphericalended metal probe. Thus, there can be no harm in monitoring TOF response at high current in anaesthetised patients.

It has been documented that some patients with a wrist circumference $>16 \mathrm{~cm}$ required delivered currents in excess of $\mathbf{4 0} \mathrm{mA}$ to achieve supramaximal muscular re- 
sponses, whilst there was a poor correlation between wrist circumference and the current needed for supramaximal muscular contraction. ${ }^{5}$ In no patient was the circumference of the wrist above $16 \mathrm{~cm}$ in this study.

In most previous studies ${ }^{1-3,5}$ a force transducer was used to evaluate neuromuscular responses. In contrast, neuromuscular responses were assessed accelographically in the present study. Viby-Mogensen et al. ${ }^{11}$ reported a close relationship between accelographical TOFR measured with an acceleration transducer and mechanical TOFR measured with a force transducer in the mechanical TOFR range 0 to 0.70 , although when mechanical TOFR $>0.70$, the accelographic TOFR tended to be higher than the mechanical TOFR. Additionally, in the absence of neuromuscular blockade accelographic TOFR is greater than 1.0.4,11 On the other hand, it has been reported that $T_{1}$ twitch height measured accelographically is not different from that measured mechanically. ${ }^{12}$ However, Silverman et al. $^{4}$ demonstrated that the accelograph did not display a twitch response until it became $3 \%$ of its baseline height. Kirkegaard-Nielsen ${ }^{13}$ also reported that, even when the force transducer was used to measure a twitch response, the minimum detectable level on the digital display was about 3 to $4 \%$ and, therefore, one or two responses to TOF were often felt before any responses had been detected mechanically. Then, when measured accelographically or mechanically, the return of the first, second, third, and fourth responses to TOF stimulation is delayed compared with those measured by tactile evaluation because of the low sensitivity of the acceleration or force transducer. It has been reported that the electromyograph (EMG) is more sensitive in detecting a $T_{1}$ response during profound neuromuscular blockade than the mechanical twitch response. ${ }^{14}$ Hence, in order to measure the time of return of the first, second, third, and fourth responses to TOF stimulation, the EMG is thought to be the best monitoring device.

We conclude that, in evaluating conscious subjects, 30 $\mathrm{mA}$ is the optimal stimulating current for evaluating TOF response because, using $30 \mathrm{~mA}$, the time to the return of TOF response is not different but is less uncomfortable than that produced by $40-60 \mathrm{~mA}$.

\section{References}

1 Connelly NR, Silverman DG, O'Connor TZ, Brull SJ. Subjective responses to train-of-four and double burst stimulation in awake patients. Anesth Analg 1990; 70: 650-3.

2 Brull SJ, Connelly NR, Silverman DG. Correlation of train-of-four and double burst stimulation ratios at varying amperages. Anesth Analg 1990; 71: 489-92.

3 Brull SJ, Ehrenwerth J, Silverman DG. Stimulation with submaximal current for train-of-four monitoring. Anesthesiology 1990; 72: 629-32.
4 Silverman DG, Connelly NR, O'Connor TZ, Garcia $R$ Brull SJ. Accelographic train-of-four at near-threshold currents. Anesthesiology 1992; 76: 34-8.

5 Kopman AF, Lawson D Milliamperage requirements for supramaximal stimulation of the ulnar nerve with surface electrodes. Anesthesiology 1984; 61: 83-5.

6 Viby-Mogensen J. Clinical assessment of neuromuscular transmission. Br J Anaesth 1982; 54: 209-23.

7 Berger JJ, Gravenstein JS, Munson ES. Electrode polarity and peripheral nerve stimulation. Anesthesiology 1982; 56: 402-4.

8 Lippmann $M$, Fields WA. Burns of the skin caused by a peripheral-nerve stimulator. Anesthesiology 1974; 40: 82-4.

9 Gray $J A$. Nerve stimulators and burns (Letter). Anesthesiology 1975; 42: 231-2.

10 Kopman $A F$. A safe surface electrode for peripheral-nerve stimulation. Anesthesiology 1976; 44: 343-5.

11 Viby-Mogensen J, Jensen E, Werner M, Kirkegaard Nielsen $H$. Measurement of acceleration: a new method of monitoring neuromuscular function. Acta Anaesthesiol Scand 1988; 32: 45-8.

12 May $O$, Kirkegaard Nielsen $H$, Werner MU. The acceleration transducer - an assessment of its precision in comparison with a force displacement transducer. Acta Anaesthesiol Scand 1988; 32: 239-43.

13 Kirkegaard-Nielsen H, Helbo-Hansen HS, Severinsen IK, Lindholm P, Pedersen HS, Schmidt MB. Comparison of tactile and mechanomyographical assessment of response to double burst and train-of-four stimulation during moderate and profound neuromuscular blockade. Can $\mathrm{J}$ Anaesth 1995; 42; 21-7.

14 Kopman AF. The relationship of evoked electromyographic and mechanical responses following atracurium in humans. Anesthesiology 1985; 63: 208-11. 